\title{
Power Transmission Lines Congestion Control with Proper Placement of Smart Wire
}

\author{
Pallavi Choudekar, Divya Asija, Upasana Gaur
}

\begin{abstract}
Congestion is severe problem that affects the power system security as it violates the various operating limits of the power system so congestion management is an important task for independent system operator. For managing congestion, smart wire module has been used in series with transmission line. When smart wire is connected in series with most congested line, there is improvement in voltage profile, reduction in transmission line loading and losses. Transmission Congestion Distribution Factor (TCDF) is calculated to know congestion in lines and congestion is managed with the help of smart wire module. It is observed that value of TCDF also reduced when smart wire is connected. Work has been carried out on IEEE 15 bus system on MATLAB.
\end{abstract}

Index Terms: Smart wire, Congestion, TCDF (Transmission Congestion Distribution Factor), PTCDF (Active Power Transmission Congestion Distribution Factor), QTCDF (Reactive Power Transmission Congestion Distribution Factor).

\section{INTRODUCTION}

In deregulated power system, due to increase in load demand generating stations increase generation to match load demand. Building of new transmission line is not possible because of economic and environmental issues. Due to limited capacity of existing transmission line, transmission line gets overloaded and losses increase, voltage stability decreases and it results in blackout and system collapse. Transmission congestion is a frequent issue for the system operators.

Various methods of congestion management are studied in literature are generation rescheduling, use of Distributed Generators, use of FACTS devices.

The smart wire module was designed for congestion management. It introduces in the transmission line an extra reactance that restricts overflow of current. The module for smart wire comes into play when congestion occurs in the line [1],[2]. It has been discovered that FACTS devices are utilized to control power quality in the transmission line.

Using the FACTS controller system, congestion management is don generic algorithm is used with objective

of loss reduction and maintaining voltage stability when
FACTS devices are placed at optimal location. Several algorithms are introduced for an optimal location with different cases. [3],[4]. Smart wire technology and its prototype is used for congestion management and loadability improvement [5]. It is also found in literature that the distributed static series compensator is used to achieve power flow control in line. DFACTS devices are used to connect directly across the high voltage line to improve congestion with lower cost [6]. Another study on grid power flow control via smart wire reveals that line impedance is elevated by injecting the single-turn transformer's predefined reactance value [7]. There is competition in the market for congestion in the power sector due to market settlement, which refers to overloading of transmission lines and transformers. Buyers would like to purchase electricity from the energy market's cheapest cost sources. The chances of congestion are high, as the deregulated market is a monopoly market. Congestion is undesirable and to maintain system security should be alleviated [8]. It was found in the literature that FACTS devices are used to control the power flows in the transmission line by changing line reactance. Distributed FACTS is used for congestion management as FACTS devices are costly when used for large power system. For power control, distributed FACTS devices are used which operate at lower cost than FACTS devices.[9],[10]. Authors have used smart wire for managing congestion and results are compared when TCSC is used in series with transmission line [11-13].

Among all methods for the congestion management, smart wire modules are used in the work. New line construction is costly, rescheduling of load gives lower efficiency, but the smart wire module results in efficient and low-cost method.

\section{SMART WIRE}

In Smart Wire consists of an electromechanical switch (SM). It is normally closed switch which is used for bypassing the smart wire module, whenever smart wire module is not energized. The single turn transformer (STT) magnetizing inductance (tuned to a desired value) is given into the line when SM is made open.

The module is bypassed and a minimal level of reactance (corresponding to the STT leakage reactance) is provided in the line when SM closed. S1

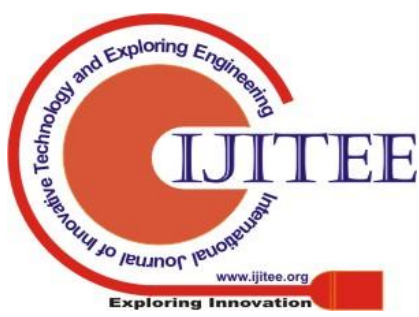


is a thyristor switch, which provides a sub-cycle response, and also by-passes the module quickly under faulty circumstances. Sustained loss of thyristor pair is thus prevented. It also increases the contact life for the relay.

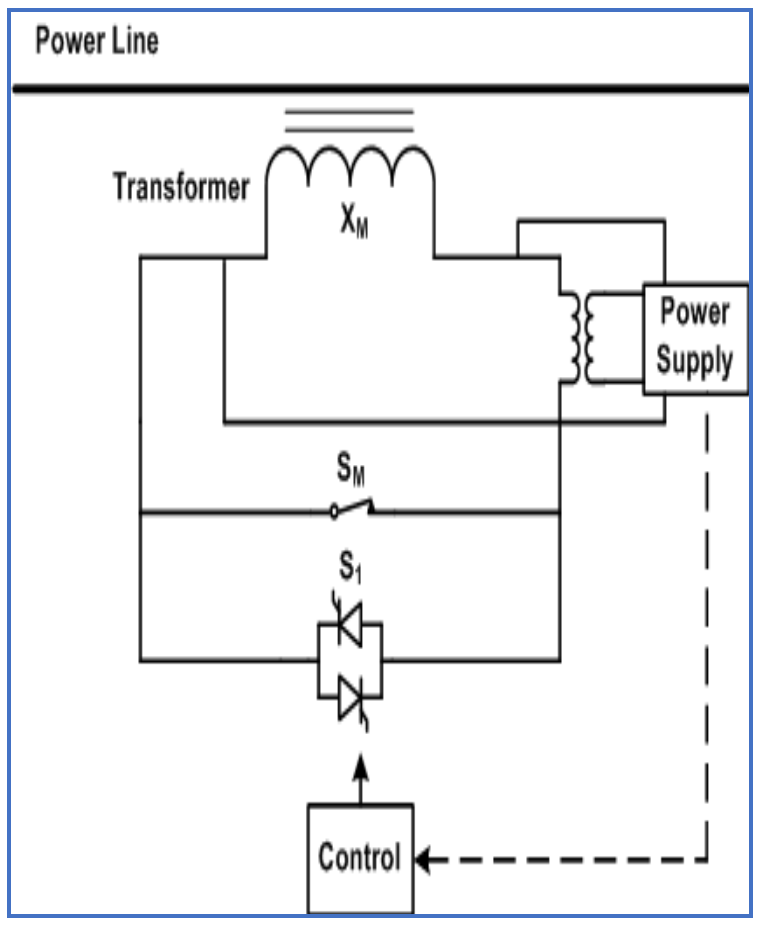

Fig. 1 Circuit schematic of Smart Wire

When the current in a transmission line is more than its rated value, smart wire modules are switched in. Due to thus transmission line impedance increases and current gets diverted in the transmission lines which are operating below their limits. Congested transmission lines are equipped with smart wire modules for automatically controlling the current flow in heavily loaded transmission lines or lines which gets overloaded due to contingency condition. Circuit schematic of Smart Wire is shown in Fig. 1.

Smart wire modules are used in power system for directing current from one part of the network to the other. Further by bringing the system to its maximum power transfer capacity the utilization of all the lines in the network can be gradually improved. It too enhances the reliability of the system with the capability to share the overload conditions between lines.

By diverting the excess current to other lines, a SW system restores a secure system operation under contingency conditions. It too also improves the transmission capacity under such conditions. Finally, a self-healing network with controllable valves is obtained. However, if a stable system operation is guaranteed without any interference between the modules and the networks, the benefits from the SW modules can only be realized.

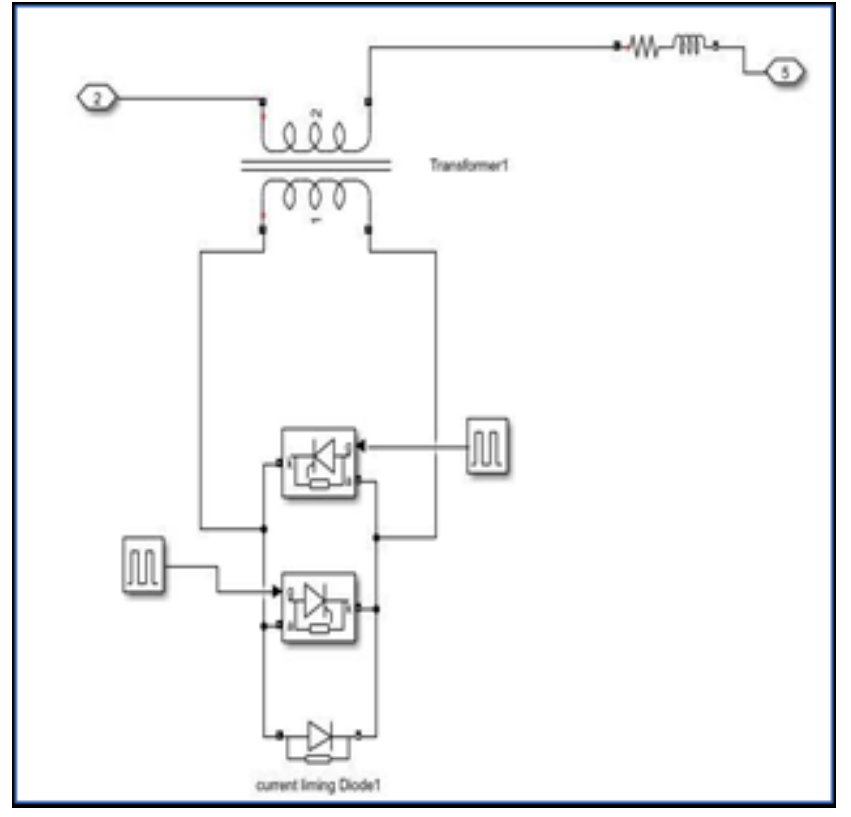

Fig. 2 Smart Wire Module

smart wire consists of a single turn transformer, a diode which is called as current limiting diode. It also has a static switch which is normally closed. The turn ratio of single turn transformer is taken to reflect minimum secondary side current in faulty condition. Smart wire module is shown in Fig.2.

\section{Transmission Congestion Distribution Factor (TCDF)}

Power flow constraints are based on Transmission Congestion Distribution Factors (TCDFs) which is defined as the variation in real power flow $\left(\mathrm{P}_{\mathrm{ij}}\right)$ through a transmission line $\mathrm{k}$, linked between buses $\mathrm{i}$ and $\mathrm{j}$ which occurs because of injection of active power at bus $\mathrm{j}$. TCDF for line $\mathrm{k}$ can be written as

$T C D F_{j}^{k}=\frac{\Delta P_{\mathrm{ij}}}{\Delta P_{i}}$

TCDF denotes change in active power flow through transmission line because of injection of active power at bus j.

Active Transmission Congestion Distribution Factor (PTCDF) is given by equation (2)

$P T C D F_{j}^{k}=\frac{\Delta P_{i j}}{\Delta P_{i}}$ 
Reactive Transmission Congestion Distribution Factor (QTCDF) is given by equation (3)

$Q T C D F_{j}^{k}=\frac{\Delta Q_{i j}}{\Delta Q_{i}}$

Proposed work is carried out in IEE 15 bus test system in MATLAB. It consists of a substation that acts as the source of total $\mathrm{P}=1.26 \mathrm{MW}$ and $\mathrm{Q}=1.28 \mathrm{MVAR}$ generation, total $\mathrm{P}=1.23 \mathrm{MW}$ and $\mathrm{Q}=1.25 \mathrm{MVAR}$ load, total $\mathrm{P}=0.04 \mathrm{MW}$ active power loss and $\mathrm{Q}=0.03 \mathrm{MVAR}$ reactive power loss. Total 14 loads are connected across the 14 buses except the slack bus. The total system has an $11 \mathrm{KV}$ base voltage at $100 \mathrm{MVA}$ and $60 \mathrm{~Hz}$ frequency. IEEE 15 bus system is shown in Fig. 3

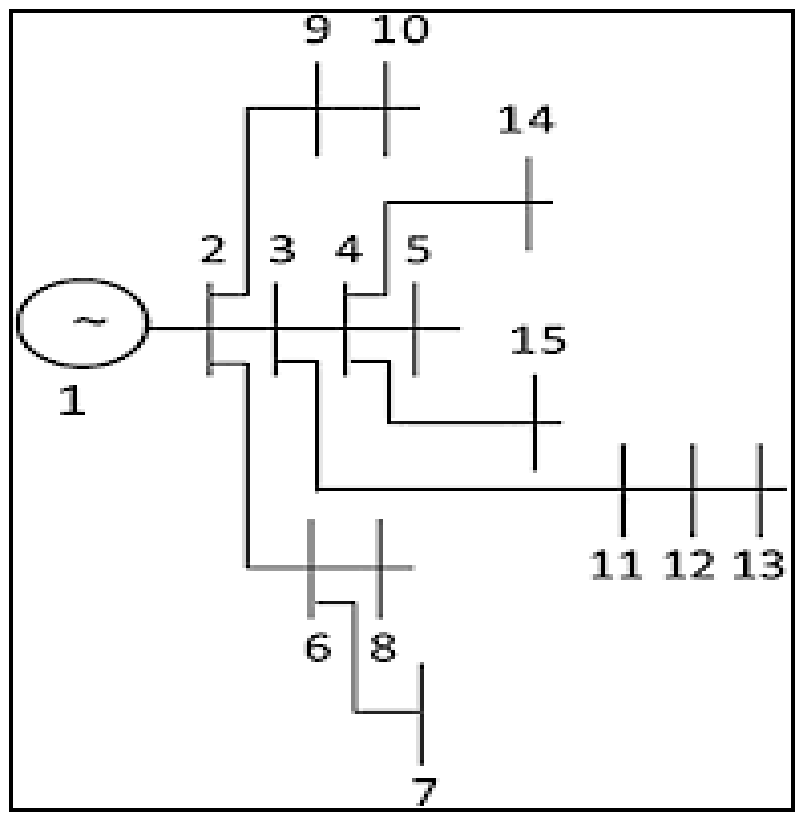

Fig. 3 IEEE 15 Bus System

\section{ALGORITHM TO CALCULATE TCDF}

Step 1: Using MATLAB Simulink software Start the MATLAB software design the IEEE-15 bus system.

Step 2: Enter the data into IEEE-15 bus system model.

Step 3: Formulate the Jacobian matrix and Admittance matrix to accomplish the load flow analysis using Newton Raphson method.

Step 5: Perform the load flow analysis to find the most overloaded transmission line causing congestion in the network.

Step 6: Model the smart wires as per the Fig. 2 and input the required data in to it.

Step 7: Create congestion in any of the transmission line by incrementing the load and accordingly place smart wires in that line to resolve the congestion issue.

Step 8: Repeat the step 7 for other 14 loads having individual interlinked transmission line.

Step 9: Calculate the TCDF for the system with and without the smart wires.

\section{RESULTS AND DISCUSSIONS}

Table I shows the comparison of the phase current and reactive power losses with and without smart wire module. It has been found that these parameters have improved by a considerable value thereby enhancing the overall system performance.

During congestion the current profile suddenly rises and voltage profile deteriorates. Table II shows the phase current and reactive power losses value after installation of smart wires. The per phase current in the system which is high in magnitude is being reduced to a nominal value. Thus, smart wire module has shown to improve the system reliability by making the system parameters under limits.

TABLE I : COMPARISON OF PHASE CURRENT AND REACTIVE POWER LOSSES WITH AND WITHOUT THE SMART WIRE

\begin{tabular}{|c|c|c|c|c|}
\hline \multirow{2}{*}{$\begin{array}{c}\text { INCREMENT } \\
\text { IN LOAD }\end{array}$} & \multicolumn{2}{|c|}{ Without Smart Wire } & \multicolumn{2}{c|}{ With Smart Wire } \\
\cline { 2 - 5 } & $\mathrm{I}_{\mathrm{ph}}(\mathrm{A})$ & $\begin{array}{c}\text { REACTIVE } \\
\text { POWERLOSSES } \\
\text { (MVAR) }\end{array}$ & $\mathrm{I}_{\mathrm{ph}}$ (A) & $\begin{array}{c}\text { REACTIVE } \\
\text { POWER } \\
\text { LOSSES } \\
\text { (MVAR) }\end{array}$ \\
\hline $40 \%$ & 33.49 & 0.04 & 6.321 & 0.03 \\
\hline
\end{tabular}

Table II shows improvement in voltage profile after installation of smart wire module. Voltage profile is improved with the proposed module that is from 0.9899 pu to 1.0987 pu at load bus.

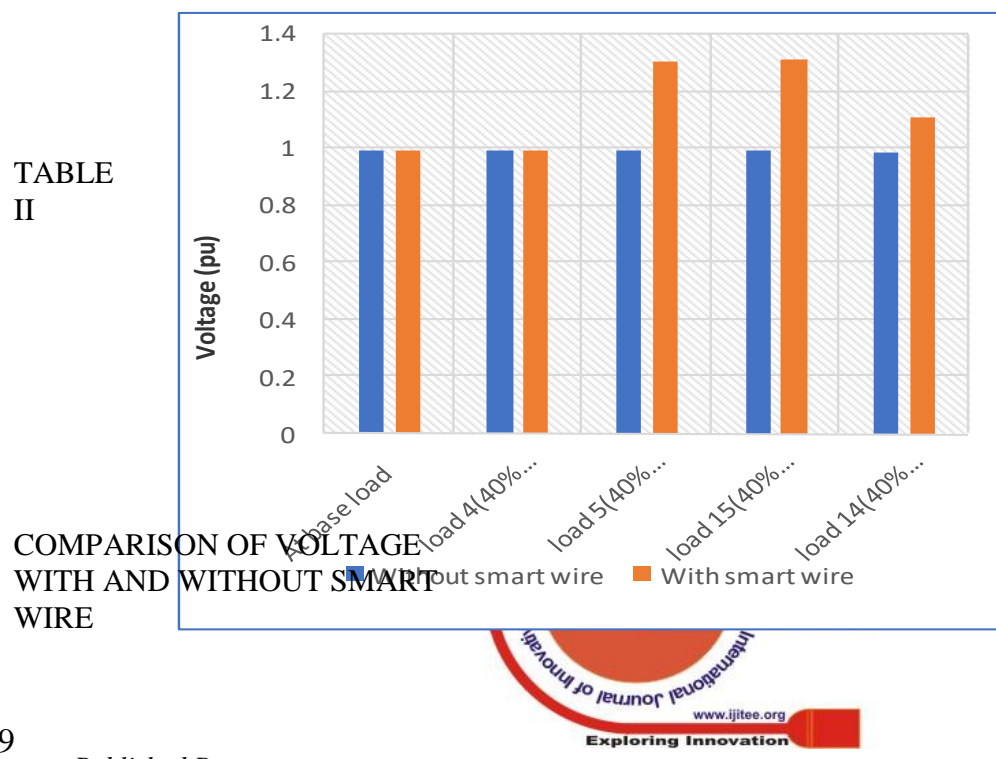




\begin{tabular}{|c|c|c|}
\hline $\begin{array}{c}\text { INCREMENT IN } \\
\text { LOAD }\end{array}$ & $\begin{array}{c}\text { WITHOUT SMART } \\
\text { WIRE (VOLTAGE (PU)) }\end{array}$ & $\begin{array}{c}\text { WITH SMART WIRE } \\
\text { (VOLTAGE (PU)) }\end{array}$ \\
\hline $40 \%$ & 0.9899 & 1.0987 \\
\hline
\end{tabular}

As per the TABLE II, the voltage level improves to approximately 1 pu with smart wire module when load is incremented by $40 \%$.

Fig. 4. Comparison of Current with Load Variation (Graphical Representation).

Fig. 4 shows variation of current with load with increment in load from base load to its some percentage level i.e. from 0 to $40 \%$, with inclusion and without inclusion of smart wire module. At the base load of $71.41 \mathrm{KVAR}$, current is observed as $33.49 \mathrm{~A}$ in normal operating state. But after the introduction of smart wire module, current reduces up to $6.321 \mathrm{~A}$ as observed for load at bus 4 . When load is incremented up to $40 \%$ i.e. $135.717 \mathrm{KVAR}$, current is observed as $6.321 \mathrm{~A}$ in normal state. But it again shows improvement with the smart wire module in line 4-5 and current is observed in load 7 as 6.27A. The graphical representation shows how voltage profile and current improves when there is increment in load from base load to $40 \%$ of base load along with and without smart wire module. It is shown in Fig. 5.
Fig. 5. Comparison of Voltage with Load Variation (Graphical Representation).

TABLE III :COMPARISON OF TCDF VALUES WITH AND WITHOUT SMART WIRE

\begin{tabular}{|c|c|c|}
\hline & Without Smart Wire & With Smart Wire \\
\hline & & \\
\hline PTCDF & 1.13 & 1.11 \\
\hline QTCDF & 1.07 & 1.05 \\
\hline
\end{tabular}

In TABLE III, improvements in TCDF values i.e. (PTCDF and QTCDF) is shown with and without congestion. Congestion has been removed to a significant level due to the presence of smart wire module.

\section{CONCLUSSIONS}

For efficient and reliable operation of transmission power system various congestion and its management techniques must be known. In this paper smart wire module has been inserted in the transmission line to overcome with the congestion condition. TCDF has been calculated to find the effect of smart wire module on the whole system parameters. After analysis of system parameters, it has been concluded that smart wire modules when introduced in the network on a couple of overloaded transmission lines has reduced the TCDF significantly.

\section{REFERENCES}

1. Sananda Pal, Samarjit Sengupta, "Congestion Management of a Multi-bus Transmission System using Distributed Smart Wires", International conference on Control, Instrumentation, Energy and Communication (CIEC), 2014, pp.417-419

2. Sananda Pal, A. Neogi, S. Biswas, M. Bandyopadhyay and S. Sengupta," Loss Minimization and Congestion Management of a Power Distribution Network through its Reconfiguration", International Journal of Electrical, Electronics ISSN No. (Online) : 2277-2626 and Computer Engineering 2(2): 95-99(2013) Special Edition for Best Papers of Michael Faraday IET India Summit-2013, pp. 95-98.

3. D. Venugopal, A. Jayalaxmi, "Congestion Management by Optimal Choice and Allocation of FACTS Controllers using Genetic Algorithm", International Journal of Soft Computing and Engineering (IJSCE) ISSN: 2231-2307, Vol.4, pp. 72-73, July 2014.

4. S.N. Singh, A.K. David, "Congestion Management by Optimizing FACTS Device Location", International Conference on Electric Utility Deregulation and Restructuring and Power Technologies, 2000. Proceedings. DRPT 2000, pp. 23.

5. Frank Kreikebaum, Debrup Das, Yi Yang, Member, Frank Lambert, Prof. Deepak Divan, "Smart Wires A Distributed, Low-Cost Solution

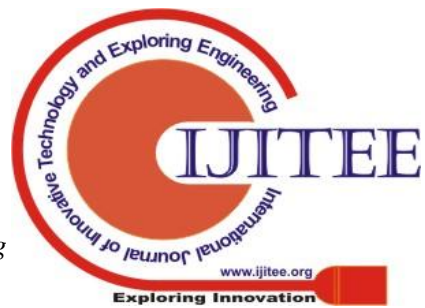


for Con-trolling Power Flows and Monitoring Transmission Lines", international conference on Innovative Smart Grid Technologies Conference Europe (ISGT Europe), 2010 IEEEPES, pp. 2-4.

6. Deepak M. Divan, William E. Brumsickle, Robert S. Schneider, Bill Kranz, Randal W. Gascoigne, Dale T. Bradshaw, Michael R. Ingram, and Ian S. Grant, " A Distributed Static Series Compensator System for Realizing Active Power Flow Control on Existing Power Lines”, IEEE transactions on power delivery, vol. 22, pp. 642-644, January 2007.

7. Jerry Melcher, "Distributed Series Reactance for Grid Power Flow Control",IEEE PES Chapter Meeting pp. 3-5, August 8, 2012.

8. Begovic,, Miroslav, "Electrical Transmission System \& Smart Grid," Selected Entries from the Encyclopedia of Sustainability Science and Technology Springer, 2013

9. D. M. Divan et al., "A Distributed Static Series Compensator System for Realizing Active Power Flow Control on Existing Power Lines," in IEEE Transactions on Power Delivery, vol. 22, no. 1, Jan. 2007 pp. 642-649.

10. D. Divan, H. Johal, "Distributed FACTS A New Concept for Realizing Grid Power Flow Control," IEEE Transactions on Power Electronics, Vol. 22, Issue 6, Nov. 2007, pp. 2253 2260. S. soft, Power System Economics Piscataway: IEEE Press, 2002, pp.6-16.

11. Abhishek, Asija D., Choudekar P., Manganuri Y., "Series Smart Wire-Managing Load and Congestion in Transmission Line", Proceedings of the 5th International Conference on Frontiers in Intelligent Computing: Theory and Applications. Advances in Intelligent Systems and Computing, vol 516. Springer, Singapore, 2017.

12. Nibha Rani, Pallavi Choudekar, Divya Asija, P Vishnu Astick, "Congestion management of transmission line using smart wire \& TCSC with their economic feasibility", 8th International Conference on Computing, Communication and Networking Technologies (ICCCNT), 2017, pp 1-5.

13. P Vishnu Astick, Divya Asija, Pallavi Choudekar, Nibha Rani, "Transmission line efficiency enhancement with inclusion of smart wires and controllable network transformers", th International Conference on Computing, Communication and Networking Technologies (ICCCNT), 2017 ,pp 1-6.

\section{AUTHORS PROFILE}

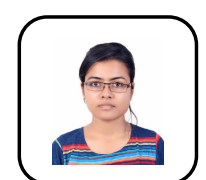

Upasana Gaur is student pursuing M. Tech in Power system. She has completed her B. Tech from NIEC, New Delhi. Her research area is power system.

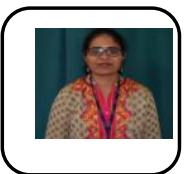

Pallavi Choudekar is pursuing Ph.D in Electrical Engineering from Amity University, Uttar Pradesh. She received her M. Tech from Gautam Buddha Technical University, Uttar Pradesh and B. E. from Pune University. She has teaching experience of 16 years. During her academic career she held various key administrative positions. She has published several research papers in reputed international journals and conferences.

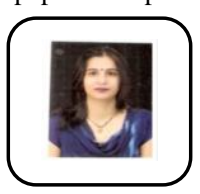

Divya Asija is pursuing Ph.D in Electrical Engineering from Amity University, Uttar Pradesh. She received her M. Tech from YMCA institute of Engineering Faridabad and B. E. from Apeejay College of Engineering, Sohna, Gurgaon. She has teaching experience of 11 years. During her academic career she held various key administrative positions. She has published several research papers in reputed international journals and conferences. Her professional interests include Congestion Management in Transmission System, Distributed Generation and other related field in power system 